\title{
Nutritional screening of older home-dwelling Norwegians: a comparison between two instruments
}

\section{Ulrika Söderhamn \\ Bjørg Dale \\ Kari Sundsli \\ Olle Söderhamn}

Centre for Caring Research-Southern Norway, Faculty of Health and Sport Sciences, University of Agder, Grimstad, Norway
Correspondence: Ulrika Söderhamn Centre for Caring Research Southern Norway, Faculty of Health and Sport Sciences, University of Agder, PO Box 509, 4898 Grimstad, Norway Tel +473723 3789

Email ulrika.soderhamn@uia.no
This article was published in the following Dove Press journal:

Clinical Interventions in Aging

14 September 2012

Number of times this article has been viewed

Background: It is important to obtain knowledge about the prevalence of nutritional risk and associated factors among older home-dwelling people in order to be able to meet nutritional challenges in this group in the future and to plan appropriate interventions. The aim of this survey was to investigate the prevalence of home-dwelling older people at nutritional risk and to identify associated factors using two different nutritional screening instruments as self-report instruments.

Methods: This study had a cross-sectional design. A postal questionnaire, including the Norwegian versions of the Nutritional Form for the Elderly (NUFFE-NO) and Mini Nutritional Assessment - Short Form (MNA-SF), background variables, and health-related questions was sent to a randomized sample of 6033 home-dwelling older people in southern Norway. A total of $2106(34.9 \%)$ subjects were included in the study. Data were analyzed using descriptive statistics and logistic regression analyses.

Results: When using the NUFFE-NO and MNA-SF, 426 (22.3\%) and 258 (13.5\%) older persons, respectively, were identified to be at nutritional risk. The risk of undernutrition increased with age. Several predictors for being at risk of undernutrition, including chronic disease/handicap and receiving family help, as well as protective factors, including sufficient food intake and having social contacts, were identified.

Conclusion: Health professionals must be aware of older people's vulnerability to risk of undernutrition, perform screening, and have a plan for preventing undernutrition. For that purpose, MNA-SF and NUFFE-NO can be suggested for screening older people living at home.

Keywords: aged, risk factors, undernutrition, screening

\section{Introduction}

Frailty and disability increase with aging as well as with the onset of multiple comorbidities. These circumstances may impact nutritional status negatively, ${ }^{1}$ and can result in inadequate food intake, which is known to lead to undernutrition., ${ }^{2,3}$ Being at risk of undernutrition or undernourished in older age is multifaceted. It has been found that advanced age, ${ }^{4-7}$ the presence of several comorbidities, ${ }^{5-7}$ hospitalization in the previous year, ${ }^{7}$ decline in intellectual activity, ${ }^{8}$ being functionally dependent,, 67 receiving help to manage daily life,,$^{7,9,10}$ and receiving meals on wheels ${ }^{11}$ are associated with undernutrition or risk of undernutrition among home-dwelling older people. Loss of a spouse, ${ }^{6,8,12}$ living alone, ${ }^{9,10}$ having a lower level of education, ${ }^{5}$ perceiving impaired health, ${ }^{7,9,11}$ and lowered quality of life $^{7}$ are further factors found to be related to impaired nutritional status in older home-living people.

These factors highlight the need to identify home-dwelling older people at nutritional risk in order to be able to prevent undernutrition. Undernutrition is defined as 
insufficient intake of nutrients, but can also be the result of inadequate absorption or metabolism of nutrients. ${ }^{3}$ In this study, nutritional risk refers to be at risk of undernutrition. According to Callen, ${ }^{13}$ screening has the potential to identify nutritional risk in older people. It can also identify characteristics associated with undernutrition and, moreover, help professionals to identify people who are not obviously undernourished. ${ }^{3}$ However, screening home-dwelling older people can be a challenge both in research and clinical practice, and it needs a simple screening instrument.

According to European nutritional screening guidelines, the Mini Nutritional Assessment $\left(\mathrm{MNA}^{\circledR}\right)$ and the Mini Nutritional Assessment - Short Form (MNA-SF) are instruments recommended for screening of older people. ${ }^{14}$ However, the full form of the MNA ${ }^{15}$ is complicated to use as a self-reporting instrument, due to the fact that some of the items included, such as body mass index and measurements of mid-arm and calf circumferences, are difficult to carry out without assistance. The MNA-SF ${ }^{16}$ contains body mass index, and is a simpler instrument to use because mid-arm and calf circumferences are not included. Therefore, it can be suitable for screening home-dwelling people ${ }^{17}$ and be used as a selfreport instrument. Likewise, Kaiser et $\mathrm{al}^{18}$ have found that the MNA-SF can be used among older community-dwelling people as well as in the clinical setting.

The MNA-SF is found to compare well with the full MNA for nutritional screening. ${ }^{16,18}$ To strengthen its use in geriatric care, the MNA-SF has recently been revised. The revised form of the MNA-SF allows use of calf circumference instead of body mass index if it is difficult to measure height and weight, for example, in disabled and immobile older people. ${ }^{18,19}$ However, when using MNA-SF as a selfreport instrument among home-dwelling older people, body mass index can be seen as the best alternative when replaced with self-reported weight and height.

Another nutritional screening instrument, developed especially as a simple self-report instrument for older people, is the Nutritional Form for the Elderly (NUFFE). ${ }^{20-22}$ In a Norwegian study of older hospitalized patients, it was found that the MNA, MNA-SF, and NUFFE could identify approximately the same number of older patients who were nutritionally at risk. ${ }^{23}$ Therefore, it would be interesting to perform nutritional screening among home-dwelling older people using both the MNA-SF and NUFFE, because both can be used as self-report instruments.

Larger studies conducted to screen and investigate the risk of undernutrition and associated factors among homedwelling older people in a Norwegian context are scarce in the literature. The number of older people is expected to increase dramatically in the future, ${ }^{24}$ and many will probably be living in their own homes. ${ }^{25}$ Therefore, it is important to perform studies to obtain knowledge of the prevalence of nutritional risk and associated factors among home-dwelling older people in order to be able to meet nutritional challenges in the future and plan appropriate interventions. The aim of this survey was to investigate the prevalence of home-dwelling older people at nutritional risk and to identify associated factors using two different nutritional screening instruments as self-report instruments.

\section{Materials and methods Study design and sample}

This survey had a cross-sectional design and was a part of a larger project about health and self-care among older people carried out in southern Norway. Data were collected during the spring and summer of 2010 using a postal questionnaire in a randomized sample of 6033 home-dwelling older people, 65 years of age or older, living in five counties in southern Norway. The National Directory of Residents was used to complete the randomization according to the directory's procedures.

Information about the survey and an invitation to participate was distributed, together with the self-report questionnaire. Answering and returning the questionnaire was considered informed consent to participate in the study; 1671 persons responded to the questionnaire. One reminder was sent, according to the rules for distribution of randomized addresses in Norway, and a further 435 persons answered and returned the questionnaire after the reminder. Thus, a total of 2106 (34.9\%) persons aged 65-96 years were included.

\section{Questionnaire}

The questionnaire used included background variables (age, gender, marital status, occupation, type of dwelling), 15 health-related questions that could be answered by "yes" or "no" (as perceived good health or not, receiving help to manage daily life or not, feeling depressed or not), three questions on an ordinal level about frequency of contacts with family, neighbors, and friends, and the Norwegian versions of two nutritional screening instruments, ie, the Nutritional Form for the Elderly (NUFFE-NO) ${ }^{22}$ and the MNA-SF. ${ }^{16}$

The NUFFE was developed in Sweden and is a nutritional screening instrument at an ordinal level with 15 three-point items. The items have the following content: weight loss, changes in dietary intake, appetite, food and fluid intake, eating 
difficulties, opportunities to purchase groceries, company at meals, activity, and number of medications. The most favorable option on each item produces a score of 0 and the most unfavorable option produces a score of 2 . Thus, the total score can range between 0 and 30 . Higher screening scores indicate a higher risk of undernutrition..$^{20,21}$ NUFFE has been translated into several languages. The Norwegian version, NUFFE-NO, ${ }^{22}$ has shown adequate psychometric properties for screening older people. In the testing study of NUFFE$\mathrm{NO}^{22}$ among older hospitalized patients, a Cronbach's alpha coefficient of 0.77 was obtained as a measure of homogeneity. In a test-retest investigation, most items showed good or very good agreement as a measure of stability. A high correlation coefficient $\left(r_{\mathrm{s}}=-0.74\right)$ between NUFFE-NO and MNA supported concurrent validity. The following cutoff points of NUFFE-NO were found, using MNA as a criterion: $<6$ (low risk of undernutrition), 6-10 (medium risk of undernutrition), and $\geq 11$ (high risk of undernutrition). ${ }^{22}$

The MNA-SF contains six of the items in the full MNA and is a nutritional screening instrument on both a nominal and ordinal level. The items have the following content: appetite, weight loss, mobility, psychological stress or acute disease, neuropsychological disease, and body mass index. The maximum score is 14 . Scores $\geq 12$ indicate good nutritional status and scores $\leq 11$ indicate a risk of undernutrition. ${ }^{16}$ Recently, a three-category scoring system for the MNA-SF has been introduced, ie, 12-14 scores indicate normal nutritional status, $8-11$ scores indicate risk of undernutrition, and 0-7 scores indicate undernutrition. ${ }^{18}$ The MNA-SF and MNA have been found to be equivalent in identifying older people at nutritional risk. ${ }^{26}$ Kaiser et al ${ }^{18}$ found the MNA-SF to be a valid screening instrument. Body mass index was excluded in the questionnaire used in the present study and replaced with a question about height and weight. Body mass index was calculated when the data were analyzed.

\section{Statistical analysis}

All analyses were performed using IBM SPSS version 19 (SPSS Inc, Chicago, IL). A $P$ value $<0.05$ was considered to be statistically significant. Missing data in the instruments were not replaced and only data from completely filled in instruments were used in the analyses. Remaining missing data were completely at random.

Descriptive statistics, ie, mean score and standard deviation for interval data, median score and interquartile range for ordinal data, and number (n) and percent ( $\%$ ) for nominal data, were used for describing the sample and the nutritional screening results. The following cutoff points were used when dichotomizing the nutritional screening results: NUFFE-NO $\geq 6$ scores and MNA-SF scores $\leq 11$, indicating risk of undernutrition, respectively, and NUFFE-NO scores $<6$ and MNA-SF scores $\geq 12$, indicating no risk of undernutrition, respectively.

In order to verify relationships between being at nutritional risk and age, the Kruskal-Wallis test was used to test differences regarding NUFFE-NO median scores and MNA-SF median scores, respectively, for three age groups, ie, 65-74 years, 75-84 years, and $85+$ years. The Mann-Whitney $U$ test was used to identify any differences between these age groups. One-way analysis of variance using the Bonferroni post hoc test was used to test for differences in body mass index values between the three age groups. The $t$-test for nonrelated samples was used to test for differences in age between women and men and differences in age between participants and dropouts, respectively. The chi-square test was used to test for differences between the proportions of women and men among the dropouts.

To investigate for possible predictors of nutritional risk using the NUFFE-NO and MNA-SF, two multiple forward stepwise conditional logistic regression analyses were performed. The dependent variable was the dichotomized NUFFE-NO scores (the first regression analysis) and MNA-SF scores (the second regression analysis), respectively, and being at risk of undernutrition was coded as 1 and being at no risk of undernutrition was coded as 0 . The choice of independent variables was based on variables that in univariate analyses reached a $P$ value $<0.2^{27}$ when comparing the variables of being at risk of undernutrition or not using scores from the two screening instruments, respectively. However, the majority of variables showed a $P$ value $<0.001$ in the univariate analyses. The independent variables included were: age, body mass index (not included in the second regression analysis because body mass index is an item in the MNA-SF), frequency of contact with neighbors, frequency of contact with friends, and frequency of contact with family. Dummy variables, coded to differentiate the binary status of each of these items were: gender, marital status, type of dwelling, profession, perceived health, receiving help to manage daily life, perceived helplessness, loneliness, being depressed, feeling satisfied with life, having chronic disease/handicap, being active, eating sufficiently, preparing food (not included in the second regression analysis), having access to meals, receiving home nursing, receiving home help, and receiving family help. 


\section{Ethical approval}

The Declaration of Helsinki ${ }^{28}$ and ethical standard principles ${ }^{29}$ were used to guide the authors when designing and performing the main project as well as the present study. The main project consisted of two projects ${ }^{30,31}$ that were approved by the Regional Committee for Medical Research Ethics in southern Norway (REK sør-øst D 2009/1299 and REK sør-øst A 2009/1321). Use of the data collected ${ }^{30,31}$ in the present study was approved by the same committee (REK sør-øst D 2011/2588).

\section{Results}

Sample

Background variables of the sample $(n=2106)$ are presented in Table 1. The sample consisted of approximately the same number of men and women, but the mean age of the women was slightly greater $(P=0.022)$ than that of the men. The mean age of the total sample was $74.5 \pm 6.9$ years, which was lower than the mean age of the dropouts $(\mathrm{n}=3897$, mean $77.3 \pm 8.0 ; P<0.001)$. The proportion of women was higher among the dropouts than among the participants $(P<0.001)$.

\section{Nutritional screening results}

The screening results using NUFFE-NO $(n=1907)$ showed a median score of 3 (interquartile range 2-5). A total of $1481(77.7 \%)$ individuals had a score $<6$, indicating no risk of undernutrition, and $426(22.3 \%)$ individuals had a score $\geq 6$, indicating risk of undernutrition. Of those people

Table I Background variables of sample $(n=2106)$

\begin{tabular}{lll}
\hline Background variables & \\
Age of sample & Mean \pm SD & $74.5 \pm 6.9$ \\
Age of men & Mean \pm SD & $74.2 \pm 6.7$ \\
Age of women & Mean \pm SD & $74.9 \pm 7.2$ \\
Gender & Men $\mathrm{n}(\%)$ & $1043(49.5)$ \\
& Women $\mathrm{n}(\%)$ & $1063(50.5)$ \\
Marital status & Single $\mathrm{n}(\%)$ & $179(8.5)$ \\
& Married/cohabitating, $\mathrm{n}(\%)$ & $1408(66.9)$ \\
& Widow/widower, $\mathrm{n}(\%)$ & $495(23.5)$ \\
Type of dwelling & Missing, $\mathrm{n}(\%)$ & $24(\mathrm{I} .1)$ \\
& Own home, $\mathrm{n}(\%)$ & $2026(96.2)$ \\
& Residential living, $\mathrm{n}(\%)$ & $52(2.5)$ \\
Occupation & Missing, $\mathrm{n}(\%)$ & $28(\mathrm{I} .3)$ \\
& Professional, $\mathrm{n}(\%)$ & $388(18.4)$ \\
& White collar, $\mathrm{n}(\%)$ & $530(25.3)$ \\
& Blue collar, $\mathrm{n}(\%)$ & $984(46.7)$ \\
Body mass index & Homeworker, $\mathrm{n}(\%)$ & $123(5.8)$ \\
\hline
\end{tabular}

Abbreviation: SD, standard deviation. at risk of undernutrition, $356(18.7 \%)$ had a score of 6-10, indicating medium risk of undernutrition, and $70(3.7 \%)$ had a score $\geq 11$, indicating high risk of undernutrition.

The screening results using MNA-SF $(n=1915)$ showed a median score of 14 (interquartile range 12-14). The majority of the sample $(n=1657,86.5 \%)$ had a score $\geq 12$, indicating no risk of undernutrition, and 258 (13.5\%) had a score $\leq 11$, indicating risk of undernutrition. Of those who had a score $\leq 11,226(11.8 \%)$ had a score of $11-8$, indicating risk of undernutrition, and $32(1.7 \%)$ had a score $\leq 7$, indicating undernutrition. When testing for differences between the three age groups regarding median NUFFE-NO scores, median MNA-SF scores, and mean body mass index scores, respectively, the risk of undernutrition was found to increase and the body mass index values to decrease with advancing age (Table 2).

\section{Predictors for risk and no risk of undernutrition}

Using NUFFE-NO scores as the dependent variable, ten predictors emerged in the first logistic regression analysis. Being single, feeling lonely, being depressed, having a chronic disease or handicap, receiving home nursing, and receiving family help were found to be significantly associated with risk of undernutrition. Being professional or a white collar worker, being active, eating sufficiently, and having contact with neighbors were found to be protective against risk for undernutrition (Table 3).

In the second logistic regression analysis, nine predictors emerged using MNA-SF scores. Six of these were found to be significantly associated with risk of undernutrition, ie, female gender, receiving help to manage daily life, perceiving helplessness, having a chronic disease or handicap, receiving home help, and receiving family help. Three predictors, ie, eating sufficiently, having contact with family, and having contact with neighbors were protective against risk for undernutrition (Table 3).

\section{Discussion}

The aim of this survey was to investigate the prevalence of home-dwelling older people at nutritional risk and to identify associated factors using two different nutritional screening instruments as self-report instruments. The screening results showed a prevalence of home-dwelling older people at nutritional risk that differed between $13.5 \%$ and $22.3 \%$, depending on which of the two nutritional screening instruments that was used. The lowest prevalence was found using the 
Table 2 Nutritional screening results using two instruments and BMI in relation to three age groups

\begin{tabular}{|c|c|c|c|c|}
\hline & $\begin{array}{l}\text { Age group I } \\
65-74 \text { years } \\
n=I \mid 84\end{array}$ & $\begin{array}{l}\text { Age group } 2 \\
75-84 \text { years } \\
n=694\end{array}$ & $\begin{array}{l}\text { Age group } 3 \\
85+\text { years } \\
n=228\end{array}$ & $P$ value \\
\hline \multirow[t]{2}{*}{ NUFFE-NO median (IQR) } & $3(I-4)$ & $4(2-6)$ & $5(3-8)$ & $<0.00 I^{a}$ \\
\hline & $\mathrm{n}=1084$ & $\mathrm{n}=624$ & $\mathrm{n}=199$ & \\
\hline \multirow[t]{2}{*}{ MNA-SF median (IQR) } & $14(13-14)$ & $13(12-14)$ & $13(11-14)$ & $<0.00 I^{\mathrm{a}}$ \\
\hline & $\mathrm{n}=1093$ & $\mathrm{n}=628$ & $\mathrm{n}=194$ & \\
\hline \multirow[t]{2}{*}{$\mathrm{BMI}$, mean $\pm \mathrm{SD}$} & $26.0 \pm 3.7$ & $25.1 \pm 3.6$ & $24.1 \pm 3.5$ & $<0.00 I^{\mathrm{b}}$ \\
\hline & $\mathrm{n}=1155$ & $\mathrm{n}=676$ & $\mathrm{n}=215$ & \\
\hline
\end{tabular}

Notes: ${ }^{p} P<0.00 \mathrm{I}$ between all age groups; ${ }^{\mathrm{b}} \mathrm{P}=0.00 \mathrm{I}$ between age groups 2 and $3 ; P<0.00 \mathrm{I}$ between I and 2 , and I and 3 .

Abbreviations: NUFFE-NO, the Norwegian version of the Nutritional Form For the Elderly; MNA-SF, Mini Nutritional Assessment - Short Form; BMI, body mass index; $I Q R$, interquartile range.

MNA-SF. This result can be compared with that reported by Johansson et $\mathrm{al}^{4,11}$ who found that $14.5 \%$ and $17 \%$, respectively, of older Swedish home-living people were at risk of undernutrition or were undernourished, when using the MNA. In a study of older Taiwanese individuals, Tsai et $\mathrm{al}^{32}$ found a similar prevalence of $15 \%$ using the MNA.

To our knowledge, nutritional screening studies using the MNA-SF among home-dwelling older people are scarce. However, Ülger et $\mathrm{a}^{33}$ have used the MNA-SF to screen older people living at home and visiting a geriatric outpatient clinic in Turkey. They found that $28 \%$ were at risk of undernutrition, ie, a higher prevalence than in our study. However, it can be expected that older people visiting a clinic were a more homogeneous group with respect to personal health, and thereby had a higher risk of undernutrition, because disease is known to have a negative effect on nutritional status. ${ }^{5-7}$ In our study, the sample is assumed to mirror the heterogeneity of home-dwelling older people, ie, from healthy younger older people to very old people who are expected to be suffering from illness and disease.

Other similar studies using the MNA performed among older people in south India ${ }^{34}$ and China ${ }^{6}$ showed that about $63 \%$ and $44 \%$, respectively, were at risk of undernutrition or were undernourished. These results suggest that cultural and socioeconomic factors in non-western countries have a profound effect on nutritional status in older people.

Using the NUFFE-NO resulted in a higher prevalence of nutritional risk compared with the MNA-SF. In a Swedish population study ${ }^{9}$ of 75 -year-old home-dwelling people, the same prevalence of nutritional risk, ie, $22.3 \%$, was obtained using the NUFFE. A similar prevalence $(20.3 \%)$ was also reported by Tomstad et $\mathrm{al}^{10}$ when screening a group of homedwelling older Norwegian people using the NUFFE-NO.

An explanation for the different screening results using the MNA-SF and NUFFE-NO could be that the instruments were differently constructed with different numbers of items. For example, three of the six items of the MNA-SF focus on psychological stress or acute disease, neuropsychological disease, and body mass index, ${ }^{14,16}$ which do not correspond with any of the 15 items in the NUFFE-NO. ${ }^{22}$ It is possible that items regarding psychological stress and neuropsychological disorders may be difficult to assess and report by the older persons themselves. There is also some uncertainty regarding self-reported height and weight. However, in a Norwegian study of older patients in a medical hospital, the MNA-SF and NUFFE-NO could identify an equal number of patients at nutritional risk. ${ }^{23}$ In a hospital context, measuring of height and weight can be assumed to be more reliable. Furthermore, older hospitalized patients are a more homogeneous group than home-dwelling older people, so the instruments in the present study may identify a more dissimilar number of people at nutritional risk. The 15 items in the NUFFE-NO reflect risk factors of undernutrition, ${ }^{21,22}$ and it can be assumed that the NUFFE-NO can identify more people at nutritional risk at an earlier stage than the MNA-SF. This is important, because it is an advantage to treat declining nutritional status at an early stage.

In the study of hemodialysis patients, Tsai and Chang ${ }^{35}$ found that the Taiwanese-specific MNA and MNA-SF did not identify a similar number of patients at nutritional risk. The MNA-SF identified fewer patients than did the MNA. In their study, ${ }^{35}$ the result obtained was discussed in a similar way to ours regarding the dissimilar screening results using the NUFFE-NO and MNA-SF. According to Tsai and Chang, ${ }^{35}$ one reason why MNA-SF identified fewer hemodialysis patients at nutritional risk was that this instrument has only six items and the content of the items could not reflect, for example, the uniqueness of patient appetite, medication, fluid intake, and health status.

Several predictors for risk of undernutrition emerged in the two regression analyses. Some of these were identical, ie, 
having chronic disease/handicap, receiving family help, eating sufficiently, and having contact with neighbors. Chronic disorders are well known to affect nutritional status in a negative way. ${ }^{5,6,8,36}$ Similarly, having depression or depressive symptoms has been suggested to be closely related to risk of undernutrition. ${ }^{4,73,37}$ This was also emphasized in the present study, because being depressed was a predictor using the NUFFE-NO in the first regression analysis. Therefore, health professionals working in geriatric care have to be aware of the negative impact of disease on nutritional status in older people.

Receiving family help was identified as a predictor using both instruments. This is consistent with other studies that have shown a close relationship between receiving help and risk of undernutrition. ${ }^{9}{ }^{10}$ Furthermore, receiving home nursing and home help also emerged as predictors in the first and the second regression analysis, respectively. In addition, perceived helplessness was a predictor in the second regression analysis, which was also identified in a study by Tomstad et al. ${ }^{10}$ These factors highlight the close relationship between lower self-care ability and risk of undernutrition. ${ }^{10,30,31,38}$ In other studies, functional dependency ${ }^{6,733}$ and disability ${ }^{12}$ have also been found to be related to risk of undernutrition. Consequently, physical impairment requires special attention. ${ }^{36}$

Eating sufficiently was a protective factor using both instruments. Older age is associated with changes in food intake, ${ }^{39}$ and a decreased food intake and fewer meals leads to weight loss, ${ }^{40}$ which is associated with nutritional risk. ${ }^{7,34,40,41}$ Elia $^{42}$ claims that undernutrition in a hospital context is under-recognized because patient food intake is given inadequate attention. The results of our study emphasize the importance of adequate food intake for older people living in their own homes, because it prevents undernutrition. Lorefält et $\mathrm{al}^{43}$ showed in an intervention study that older people in municipal residential homes, who received enriched meals according to their requirements, could gain weight

Table 3 Predictors for being or not being at risk of undernutrition using two screening instruments

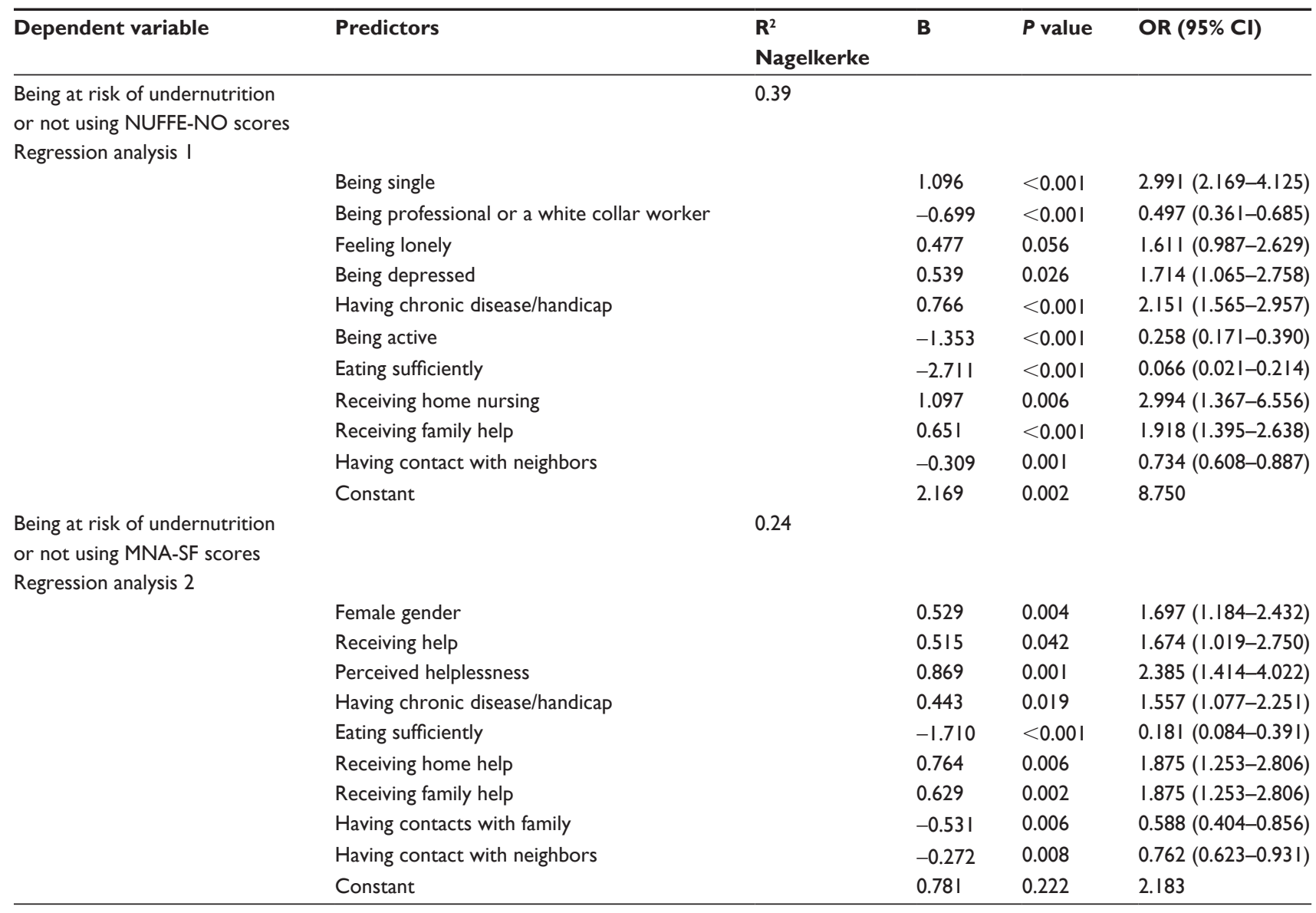

Abbreviations: $\mathrm{Cl}$, confidence interval; B, slope; MNA-SF, Mini Nutritional Assessment - Short Form; NUFFE-NO, Norwegian version of the Nutritional Form For the Elderly; OR, odds ratio; $\mathrm{R}^{2}$, determination coefficient. 
and improve their nutritional status compared with a control group receiving standard meals. These people were screened using the MNA, and the enriched meals in the intervention group were based on the screening results. ${ }^{43}$ This highlights the need for nutritional screening of all older people in contact with health professionals, who also have a responsibility to give individualized nutritional care.

Another protective predictor that emerged in the two regression analyses was contact with neighbors. Having contact with family was also a protective factor in the second regression analysis. The fact that social contact is important for preventing undernutrition is understandable because "being single" and "feeling lonely" emerged as predictors for risk of undernutrition in the first regression analysis. Living alone is a factor that has also been reported to be related to risk of undernutrition in other studies, ${ }^{10,36,44,45}$ as well as feeling lonely. ${ }^{12,44}$ Moreover, losing a spouse is found to be closely related to dietary decline in older people and thereby represents a risk for undernutrition. ${ }^{6,8,12,45}$ Likewise, being socially isolated can lead to reduction in food intake, ${ }^{36}$ and reduced social activity has been found to be related to weight loss in older people living at home. ${ }^{40,46} \mathrm{~A}$ huge challenge for health professionals, but also for society in general, is to recognize older socially isolated people and give them social support in order to prevent undernutrition.

Being active is important in order to limit nutritional risk, and this was shown in the first regression analysis. The same observation was made in a previous study, ${ }^{10}$ and being physically and socially active in older age is, in general, an important factor for good health and well-being. ${ }^{47}$

Female gender was found to be a predictor for risk of undernutrition in the second regression analysis. The greater risk in women was also identified by Wojszel ${ }^{48}$ in a study of older people in long-term care settings and by Chen et $\mathrm{al}^{49}$ among older hospitalized patients. This highlights a need for awareness of older females as a risk group for undernutrition. An explanation for this may be the greater longevity of women and the fact that many of them are living alone.

Professional or white collar occupation emerged in the first regression analysis as protective against risk for undernutrition. A lower level of education has been found to be a risk factor in other studies. ${ }^{5,50}$ According to Feldblum et al, ${ }^{50}$ education $\leq 12$ years could predict undernutrition. These results indicate that older people with higher education may have knowledge about nutrition and perhaps a better financial base for buying nourishing food products.
Age did not emerge as a predictor of risk for undernutrition in our study. A possible explanation may be the rather low mean age of our study sample. However, when scores from the two screening instruments and body mass index values were investigated in the three age groups, it was obvious that the risk of undernutrition increased with age. This is in accordance with other studies. ${ }^{4-7}$

\section{Limitations}

The response rate in this survey was low (34.9\%). However, a similar response rate $(35.1 \%)$ was obtained in a corresponding sample. ${ }^{10}$ Recruiting older people for research studies is known to be a challenge, especially when there is no face-toface meeting between the researcher and respondent. ${ }^{51}$ Older people are a heterogeneous population from the youngest old to the oldest old, and come from a variety of backgrounds, so when using instruments for data collection it is important that these are well tested in this population. ${ }^{51}$ Instruments especially developed for older people were used in our study. The MNA-SF is recommended for use among older people by health professionals, ${ }^{14}$ but can also be used as a self-report instrument. A self-report version of the MNA-SF, known as the Self MNA, has now been developed. ${ }^{52}$ The NUFFE is a self-report instrument devised for older people and is easy to complete. ${ }^{20-22}$

Nonparticipants in this study were older than the participants, indicating that the dropouts could have been suffering from illnesses preventing them from being able to fill in the self-report questionnaire. There were no exclusion criteria in this study, because it was assumed that individuals suffering from diseases affecting cognitive function would be unable to answer the questionnaire. Perhaps a further reminder could have resulted in a higher response rate, but we were not allowed to send out more than one reminder. Offering the participants help to complete the answers in the questionnaire may also have resulted in a higher response rate. On the other hand, our design with its postal questionnaire sent to a large number of older people made it impossible to undertake individual interviews.

In spite of the low response rate, the study sample consisted of a considerable number of older men and women and a wide age range. The nutritional screening results were based on fully completed instruments, so they should contain reliable data. However, generalization of the study results regarding the oldest old should be done with caution because the mean age of the sample was rather low compared with the mean age of nonparticipants. 


\section{Conclusion}

The nutritional screening results obtained using two screening instruments, ie, NUFFE-NO and MNA-SF, among homedwelling older people did not produce identical results. However, compared with other studies using these instruments in Western countries, the screening results do correspond rather well. The 15 items in the NUFFE-NO are considered to be risk factors for undernutrition, so it is assumed that the instrument can identify older people at nutritional risk at an earlier stage, and thereby identify more persons at risk, than do the six items of the MNA-SF. Predictors of nutritional risk and protective factors obtained using these two nutritional screening instruments are in accordance with predictors of nutritional risk among older people already known from other studies.

The results highlight that one fifth of home-dwelling older people are at risk of undernutrition. By using simple nutritional screening instruments developed for screening older people, nutritional risk and associated factors can be identified in this age group. Having a chronic disease or handicap and receiving family help can predict nutritional risk. Having an adequate food intake and social contact can protect against risk for undernutrition. Health professionals must be aware of older people's vulnerability to undernutrition, perform screening, and have a plan for preventing undernutrition. To that end, the NUFFE-NO and MNA-SF are recommended for screening older people living at home.

\section{Acknowledgment}

The study was financed by the Norwegian Research Council (project number 18785) and the Faculty of Health and Sport Sciences, University of Agder, Norway.

\section{Disclosure}

The authors declare that they have no conflicts of interest in this work.

\section{References}

1. Neno R, Neno M. Promoting a healthy diet for older people in the community. Nurs Stand. 2006;20(29):59-65.

2. Brownie S. Why are elderly individuals at risk of nutritional deficiency? Int J Nurs Pract. 2006;12(2):110-118.

3. Chen CC-H, Schilling LS, Lyder CH. A concept analysis of malnutrition in the elderly. J Adv Nurs. 2001;36(1):131-142.

4. Johansson Y, Bachrach-Lindström M, Carstensen J, Ek A-C. Malnutrition in a home-living older population: prevalence, incidence and risk factors. A prospective study. J Clin Nurs. 2009;18(9): 1354-1364.

5. Chen SH, Acton G, Shao JH. Relationships among nutritional selfefficacy, health locus of control and nutritional status in older Taiwanese adults. J Clin Nurs. 2010;19(15-16):2117-2127.
6. Han Y, Li S, Zheng Y. Predictors of nutritional status among community-dwelling older adults in Wuhan, China. Public Health Nutr. 2009;12(8):1189-1196.

7. Yap KB, Niti M, Ng TP. Nutrition screening among home-dwelling older adults in Singapore. Singapore Med J. 2007;48(10):911-916.

8. Kwon J, Suzuki T, Kumagai S, Shinkai S, Yukawa H. Risk factors for dietary variety decline among Japanese elderly in a rural community: a 8-year follow-up study from TMIG-LISA. Eur J Clin Nutr. 2006; 60(3):305-311.

9. Söderhamn U, Christensson L, Idvall E, Johansson A-K, Bachrach-Lindström M. Factors associated with nutritional risk in 75-yearold community living people. Int J Older People Nurs. 2012; 7(1):3-10.

10. Tomstad TS, Söderhamn U, Espnes GA, Söderhamn O. Living alone, receiving help, helplessness and inactivity are strongly related to risk of undernutrition among older home-dwelling people. Int J Gen Med. 2012;5:231-240.

11. Johansson L, Sidenvall B, Malmberg B, Christensson L. Who will become malnourished? A prospective study of factors associated with malnutrition in older persons living at home. J Nutr Health Aging. 2009;13(10):855-861.

12. Wham C, Carr R, Heller F. Country of origin predicts nutrition risk among community living older people. J Nutr Health Aging. 2011;15(4): 253-258.

13. Callen BL. Nutritional screening in community dwelling older adults. Int J Older People Nurs. 2011;6(4):272-281.

14. Kondrup J, Allison SP, Elia M, Vellas B, Plauth M. ESPEN guidelines for Nutrition Screening 2002. Clin Nutr. 2003;22(4):415-421.

15. Guigoz Y, Vellas B, Garry PJ. Assessing the nutritional status of the elderly: the mini nutritional assessment as a part of the geriatric evaluation. Nutr Rev. 1996;54:S59-S65.

16. Guigoz Y, Lauque S, Vellas BJ. Identifying the elderly at risk for malnutrition - The Mini Nutritional Assessment. Clin Geriatr Med. 2002;18(4):737-757.

17. Phillips MB, Foley AL, Barnard R, Isenring EA, Miller MD. Nutritional screening in community-dwelling older adults: a systematic literature review. Asia Pac J Clin Nutr. 2010;19(3):440-449.

18. Kaiser MJ, Bauer JM, Ramsch C, et al; the MNA-international group. Validation of the Mini Nutritional Assessment Short-Form (MNA-SF ${ }^{\circledR}$ ): A practical tool for identification of nutritional status. J Nutr Health Aging. 2009;13(9):782-788.

19. Tsai AC, Chang T-L, Wang Y-C, Liao C-Y. Population-specific Short-Form Mini Nutritional Assessment with Body Mass Index or calf circumference can predict risk of malnutrition in communityliving or institutionalized elderly people in Taiwan. J Am Diet Assoc. 2010;110(9):1328-1334.

20. Söderhamn U, Söderhamn O. Developing and testing the Nutritional Form For the Elderly. Int J Nurs Pract. 2001;7(5):336-341.

21. Söderhamn U, Söderhamn O. Reliability and validity of the Nutritional Form For the Elderly (NUFFE). J Adv Nurs. 2002;37(1):28-34.

22. Söderhamn U, Flateland S, Jessen L, Söderhamn O. Norwegian version of the Nutritional Form for the Elderly: sufficient psychometric properties for performing institutional screening of elderly patients. Nutr Res. 2009;29(11):761-767.

23. Söderhamn U, Flateland S, Jessen L, Söderhamn O. Perceived health and risk of undernutrition: a comparison of different nutritional screening results in older patients. J Clin Nurs. 2011;20(15-16) 2162-2171.

24. Kalache A, Baretto SM, Keller I. Global ageing: the demographic revolution in all cultures and societies. In: Johnson ML, editor. The Cambridge Handbook of Age and Ageing. Cambridge, UK: Cambridge University Press; 2005:30-46.

25. Ryan AA, McCann S, McKenna H. Impact of community care in enabling older people with complex needs to remain at home. Int $J$ Older People Nurs. 2009;4(1):22-32.

26. Guigoz Y. The Mini Nutritional Assessment $\left(\mathrm{MNA}^{\circledR}\right)$ review of the literature - what does it tell us? J Nutr Health Aging. 2006;10(6): 466-485.

27. Altman D. Practical Statistics for Medical Research. London, UK: Chapman \& Hall/CRC; 1999. 
28. Declaration of Helsinki. Ethical principles for medical research involving human subjects. 59th WMA General Assembly. Seoul: Korea; 2008. Available from: http:/www.wma.net/en/30publications/10policies/b3/ index.html. Accessed January 30, 2012.

29. Beauchamp TL, Childress JF. Principles of Biomedical Ethics. 6th ed. Oxford, UK: University Press Inc; 2009.

30. Dale B, Söderhamn U, Söderhamn O. Self-care ability among homedwelling older people in rural areas in southern Norway. Scand J Caring Sci. 2012;26(1):113-122.

31. Sundsli K, Söderhamn U, Espnes GA, Söderhamn O. Ability for self-care in urban living older people in southern Norway. J Multidiscip Healthc. 2012;5:85-95.

32. Tsai $\mathrm{CH}$, Ho CS, Chang MC. Assessing the prevalence of malnutrition with the Mini Nutritional Assessment (MNA) in a nationally representative sample of elderly Taiwanese. J Nutr Health Aging. 2008;12(4):239-243.

33. Ülger Z, Halil M, Kalan I, et al. Comprehensive assessment of malnutrition risk and related factors in a large group of communitydwelling older adults. Clin Nutr. 2010;29(4):507-511.

34. Vedantam A, Subramanian V, Rao NV, John KR. Malnutrition in freeliving elderly in rural south India: prevalence and risk factors. Public Health Nutr. 2010;13(9):1328-1332.

35. Tsai AC, Chang M-Z. Long-form but not short-form Mini-Nutritional Assessment is appropriate for grading nutritional risk of patients on hemodialysis - a cross-sectional study. Int J Nurs Stud. 2011;48(11): 1429-1435.

36. Ahmed T, Haboubi N. Assessment and management of nutrition in older people and its importance to health. Clin Interv Aging. 2010;5: 207-216.

37. Callen BL, Wells TJ. Screening for nutritional risk in communitydwelling old-old. Public Health Nurs. 2005;22(2):138-146.

38. Söderhamn U, Bachrach-Lindström M, Ek A-C. Self-care ability and sense of coherence in older nutritional at-risk patients. Eur J Clin Nutr. 2008;62(1):96-103.

39. Alam I, Larbi A, Pawelec G, Paracha PI. Relationship between anthropometric variables and nutrient intake in apparently healthy male elderly individuals: a study from Pakistan. Nutr J. 2011;10:111
40. Sørbye LW, Schroll M, Finne Soveri H, et al. Unintended weight loss in the elderly living at home: the aged in Home Care Project (AdHOC). J Nutr Health Aging. 2008;12(1):10-16.

41. Martin CT, Kayser-Jones J, Stotts NA, Poerter C, Froelicher ES. Risk for low weight in community-dwelling, older adults. Clin Nurse Spec. 2007;21(4):203-211.

42. Elia M. Nutrition, hospital food and in-hospital mortality. Clin Nutr. 2009;28(5):481-483.

43. Lorefält B, Andersson A, Wirehn AB, Wilhelmsson S. Nutritional status and health care costs for the elderly living in municipal residential homesan intervention study. J Nutr Health Aging. 2011;15(29):92-97.

44. Ramic E, Pranjic N, Batic-Mujanovic O, Karic E, Alibasic E, Alic A. The effect of loneliness on malnutrition in elderly population. Med Arh. 2011;65(2):92-95.

45. Wham CA, Teh RO, Robinson M, Kerse NM. What is associated with nutrition risk in very old age? J Nutr Health Aging. 2011;15(4): 247-251.

46. Martin CT, Kayser-Jones J, Stotts NA, Porter C, Froelicher ES. Factors contributing to low weight in community-living older adults. J Am Acad Nurse Pract. 2005;17(10):425-431.

47. Söderhamn U, Dale B, Söderhamn O. Narrated lived experiences of self-care and health among rural-living older persons with a strong sense of coherence. Psychol Res Behav Manag. 2011;4:151-158.

48. Wojszel ZB. Determinants of nutritional status of older people in longterm care settings on the example of the nursing home in Białystok. Adv Med Sci. 2006;51:168-173.

49. Chen CC-H, Bai Y-Y, Huang G-H, Tang ST. Revisiting the concept of malnutrition in older people. J Clin Nurs. 2007;16(11):2015-2026.

50. Feldblum I, German L, Castel H, et al. Characteristics of undernourished older medical patients and the identification of predictors for undernutrition status. Nutr J. 2007;6:37.

51. Jacelon CS. Older adults' participation in research. Nurse Res. 2007; 14(4):64-73.

52. Nestlé Nutrition/Institute. Self MNA ${ }^{\circledR}$, Mini Nutritional Assessment For Adults 65 years of Age and Older; 2012. Available from: http://www mna-elderly.com/forms/Self_MNA.pdf. Accessed August 1, 2012.
Clinical Interventions in Aging

\section{Publish your work in this journal}

Clinical Interventions in Aging is an international, peer-reviewed journal focusing on evidence-based reports on the value or lack thereof of treatments intended to prevent or delay the onset of maladaptive correlates of aging in human beings. This journal is indexed on PubMed Central, MedLine, the American Chemical Society's 'Chemical Abstracts Ser-

\section{Dovepress}

vice' (CAS), Scopus and the Elsevier Bibliographic databases. The manuscript management system is completely online and includes a very quick and fair peer-review system, which is all easy to use. Visit http://www.dovepress.com/testimonials.php to read real quotes from published authors. 